\section{Adoption of Soilless Cropping Systems in Mediterranean Greenhouses: An Application of Duration Analysis}

\author{
Francisco Alcon ${ }^{1}$ \\ Department of Enterprise Economy, Technical University of Cartagena, \\ Paseo Alfonso XIII, 48, 30203 Cartagena, Murcia, Spain
}

\author{
Mari Carmen García-Martínez \\ Department of Agricultural Economy and Sociology, Valencian Institute for \\ Agricultural Research (IVIA), Carretera de Moncada-Náquera, Km 4.5, \\ 46113, Moncada, Valencia, Spain
}

\author{
María Dolores De-Miguel \\ Department of Enterprise Economy, Technical University of Cartagena, \\ Paseo Alfonso XIII, 48, 30203, Cartagena, Murcia, Spain
}

\section{María Ángeles Fernández-Zamudio \\ Horticultural Department, Valencian Institute for Agricultural Research (IVIA), Carretera de Moncada-Náquera Km 4.5, 46113, Moncada, Valencia, Spain}

Additional index words. farmer's decisions, horticulture, hazard function, greenhouse, Spain

\begin{abstract}
The Mediterranean basin holds the greatest area of horticultural crops grown under plastic in the world. Spain houses almost 50,000 ha of greenhouses and is one of the largest suppliers of European Union markets. Soilless cropping systems constitute an efficient production practice used in greenhouses and lessen the limitations arising from the ban of methyl bromide. Soilless cultivation is associated with the use of expensive technology, which makes farmers consider such adoption carefully. The aim of this work is to statistically identify the factors that significantly influence the timing of adopting soilless cultivation by using duration analysis. The study focuses on Mediterranean greenhouses, specifically horticultural producers in the southeast of Spain. The results suggest that certain individual characteristics as well as aspects of a social nature exert a favorable influence by reducing the delay in adopting soilless cultivation. Furthermore, technical complexity, commercial aspects related to price, and the repercussion of policies regulating methyl bromide use are also discussed in this work.
\end{abstract}

Recent decades have witnessed important changes in international production of horticultural crops. Furthermore, food safety and quality demands must be added to the progressive increase in consumption. Year-round demand means production must take place outside the natural season, which is the reason why the surface area of greenhouse crops has increased. The Mediterranean region houses 135,000 ha of horticultural species grown under plastic. The surface of greenhouse-covered areas is $\approx 27,700$ ha in Italy, 14,000 ha in Turkey, 10,000 ha in Morocco, and almost 50,000 ha in Spain (FAO, 2002). Spain is the main producer in Europe of fresh horticultural produce for export. Greenhouse cultivation

Received for publication 5 Oct. 2009. Accepted for publication 21 Nov. 2009.

We are grateful for the financial aid received from the Instituto Nacional de Investigaciones Agrarias (INIA) and the FEDER European Fund (Project number: RTA04-072) and also for the suggestions made by anonymous reviewers.

${ }^{1}$ To whom reprint requests should be addressed; e-mail francisco.alcon@upct.es. of the greenhouses has increased gradually, reaching 38,780 ha (MAPA, 2006).

There are a number of advantages to greenhouse production, an outstanding one being that it enables harvesting outside the natural season corresponding to the climate of each region with the profit related to price seasonality together with a notable increase in yields and final production quality. This intensive farming system increases the efficacy of the main disbursements.

Despite all these advantages, the greenhouses also have associated drawbacks, among which the most outstanding are the high investment needed to install the different components and training needs for proper management of the installations.

Demands for quality, health, and environment are also issues guaranteed by the European normative in environmental matters with this normative becoming increasingly far reaching and strict. Crop intensification and repetition lead to soil degradation and increased resistance of pathogens like Verticillium, Phytophthora, or nematodes, making soil disinfection essential. In recent decades, the most common method used to disinfect soils for vegetable growing has been the use of methyl bromide (MB). Nevertheless, the risks it poses to the environment have generated great deliberation and, after long debate, the Montreal Protocol was signed in 1987 with the decision to ban general use after 2005. An alternative to $\mathrm{MB}$ is soilless cropping systems, which appear to be a safer and more decisive alternative for the producer (Engindeniz, 2004).

Currently, soil cultivation continues to dominate; however, soilless cultivation can be considered one of the most important technological breakthroughs to have taken place in greenhouse cultivation, facilitating control of almost the whole growing cycle. Soilless cultivation systems already occupy over $20 \%$ of the total surface area of greenhouses.

There are different soilless cropping models, all of which require more or less complex technology. This system has a series of advantages and drawbacks when compared with traditional production in soil. Among the most outstanding advantages are higher efficiency in the use of production factors, above all irrigation water, fertilizers, and other chemical and plant protection products (Van Os, 1999). In closed systems, the filtered waste can be collected and disinfected, avoiding environmental pollution (Garibaldi et al., 2003). Furthermore, both quality and production of yields are increased if considered in terms of the commercial parameters for caliber, shape, uniform size, and shine. Moreover, sales planning is improved given increased regularity of production and an extended offer period. Among the drawbacks of soilless cultivation, the most important is the strong investment required given that greenhouses must be more automated, especially in fertirrigation. Regarding climatic control, if one wishes to protect the crop from the sharp drops in temperature and extend the production calendar, it may be necessary to install some type of heating system. Such equipment also 
demands a continuous energy supply, which in turn increases production costs. There is an increase in residues as a result of the plastics habitually used in greenhouses and the plant waste matter as well as the remains of artificial substrate and the final filtered wastes from the drainage water, making it essential to establish collection and recycling systems. Finally, management of the installations requires farmers to have special training while simultaneously generating greater dependency on technology, which may exclude possible use by farmers who are less motivated and less well prepared.

Bearing in mind these advantages and drawbacks, producers must give careful consideration to whether they finally decide to adopt this growing system and the associated technology package. There are a number of works on technology adoption, among which are those dealing with the new crop varieties (Ransom et al., 2003), sustainable practices (Hall et al., 2009), or technological innovations (Seo et al., 2008), among others. Nonetheless, there are very few works dealing with greenhouses, although these cropping systems are heavily dependent on technological innovation and the dynamic way in which they are developing; among those few to be found, we cite the work by Aramyan et al. (2007), which analyzes energy-saving systems in Dutch greenhouses.

In this context, the aim of this work is to statistically identify those factors significantly affecting the timing of soilless cultivation adoption and the associated technology. The study focuses on Mediterranean greenhouses, more specifically on horticultural producers in the southeast of Spain, applying duration analysis (DA), a technique that explores the timing of adoption within a dynamic framework. This framework overcomes generic limitations of cross-sectional adoption studies (Doss, 2006) considering adoption as a dynamic decision-making problem, spanning several years at least (Abadi Ghadim and Pannell, 1999).

\section{Materials and Methods}

Conceptual framework. Adoption refers to a process based on a sequence of individual decisions after which innovation is either accepted or rejected (Gatignon and Robertson, 1991). Once technology has been adopted, it brings certain benefits to those who adopt it, contributing to their social welfare (Rogers, 2003).

Although a number of technologies afford a relative advantage to farmers, their use has not always spread as quickly as it should (Feder and Umali, 1993). Farmers adopt technology depending on the expectations they have in terms of how they perceive that the advantages derived for adoption (or not) will help them achieve their objectives (Pannell et al., 2006). In turn, farmers' objectives vary greatly according to individual circumstances and personal preferences, among which are economic, social, and environmental aspects.

According to Marra et al. (2003) and Pannell et al. (2006), the perceptions on which adoption depends come from a process of learning and experience, in which the individuals concerned acquire, integrate, and evaluate the information that enables them to make the best decisions about technology. Thus, knowledge acquired during this process is unique to each individual and is based on a mixture of scientific information, personal experience, and cultural influences. Thus, the decision to adopt will be influenced by (Pannell et al., 2006):

A. Farmers' individual characteristics, which include social, personal, and cultural aspects as well as environmental, demographic, and economic factors; and

B. The characteristics inherent to the technology. The potential users should perceive an added advantage over the traditional technology they currently use.

Considering the different variables contained within the groups of motives that can encourage innovation to be adopted, the decision to adopt soilless technology in greenhouses will be more likely along the time when the subjective use that the farmer derives $\left(U_{s}\right)$ is greater than the use derived from cultivation in soil, which is the traditional production practice $\left(U_{t}\right)$. The change will take place when $U_{s}>U_{t}$. For an individual farmer, the probability of changing technology is:

$$
P_{s}=f(A, B)
$$

where $P_{s}$ is the probability of adopting soilless practices; $A$ is the vector of cross-section and time-dependent variables describing the social, cultural, and personal influences on the adoption decision; and $B$ is the vector of cross-section and time-dependent variables describing the attributes of technology that affect the adoption innovations.

Duration analysis. DA is a statistical method that considers the expected time an individual spends in one state before transition to another, studying the difference in the time, $T$, between the two alternative and exclusive states (Lancaster, 1990). In the context of technological adoption, this transition lasts from the moment at which the technology is known about until its adoption is made effective.

It is constructed as a behavioral model, in which the individual choices are modeled using cross-section data and incorporates dynamic elements to the innovation adoption.

Early works applying DA to the social sciences focused on factors affecting employment periods (Lancaster, 1972). Recently, this method has been applied to study other fields such as agriculture (Burton et al., 2003) and fishing (Smith, 2004).

In the present study into adoption of soilless technology in greenhouse production, the starting date has been set as the year in which the technology appeared on the Spanish market (1986) or the year in which the farmer began this agricultural activity in the event this was after the aforementioned year. The exit date, or end of the spell, will be the year the farmer adopted this innovation. In specific cases, there are farmers that had not adopted the technology at the date of analysis, and the end of the time spell is thus unknown. Although adoption could take place in the future, for these cases, the statistical procedure is right-censored establishing the year when data were collected (2006) as the end date of the observation period.

In each case, the objective is to analyze the sign and magnitude of the effects exerted by the explanatory variables on the length of the spell considering a homogeneous population in terms of the systematic factors affecting the random variable, $T$ (Kiefer, 1988; Lancaster, 1990). Probability theory plays a fundamental role in DA, because one can consider the probability of the end of the range instead of its length. The probability that a farmer will adopt a particular technology in period $t+d t$, given that he or she had not adopted until $t$, is defined by the hazard function.

Let $f(t)$ be the density function of the continuous probability of the random variable, $T$, where $t$ is the end of the range. Its corresponding cumulative function will be defined by:

$$
F(t)=\int_{0}^{t} f(s) d s=\operatorname{Pr}(T \leq t)
$$

Likewise, the distribution of $T$ can be expressed by the survival function, $S(t)$, the reverse of the cumulative distribution function of $T$. This defines the probability of not adopting in time $t$, in other words, the probability that $T$ is greater or equal to $t$.

$$
S(t)=1-F(t)=\operatorname{Pr}(T>t)
$$

The hazard function, $h(t)$, defines the instantaneous rate of completion of a spell at $T=t$, conditional on survival up to time $t$. Let us define as:

$$
\begin{aligned}
h(t) & =\operatorname{Lim}_{d t \rightarrow 0} \frac{P(t \leq T<t+d t \mid T \geq t)}{d t} \\
& =\operatorname{Lim}_{d t \rightarrow 0} \frac{F(t+d t)-F(t)}{d t(1-F(t))}=\frac{f(t)}{S(t)}
\end{aligned}
$$

The hazard function is a sequence of conditional probabilities continuous over a time spell (in this case, conditional probability of adoption) with $F(t), S(t)$ and $h(t)$ being the different ways of expressing the distribution of $T$.

The proportional hazard model shifts the instantaneous hazard function of survival to $t$. The hazard function reflects the effects of the explanatory variables $(X)$ and the baseline hazard function $\left(h_{0}\right)$, which can be semiparametric or follow a specific functional form according to $h_{0}$ for all individuals (Kiefer, 1988).

On the other hand, the two most commonly used parametric specifications in the duration models are the Weibull and the 
exponential distributions. The Weibull distribution is characterized by the hazard function $h(t)=\lambda p t^{p-I}$ with $\lambda>0$ and $p>0$. If $p>1$, the hazard function increases over time; by contrast, if $p<1$, this function will decrease over time, whereas if $p=1$, the function will collapse, becoming an exponential function. The exponential distribution is characterized by a constant hazard function, $h(t)=\lambda$, in which the parameter $\lambda>0$ implies that the hazard function is duration-independent.

The hazard function can be reformulated, as follows, to consider the influence of these covariables:

$$
h(t, X, \theta, \beta)=h_{0}(t, \theta) \exp (X, \beta)
$$

where $X$ is the vector of covariables independent of time, $\beta$ the associated unknown parameter vector, and $h_{0}(t, \theta)$ the baseline hazard function independent of the variables $X$.

The proportional hazard model uses an exponential specification that ensures that the hazard function is nonnegative without imposing restrictions on the impact of the covariates on the hazard. The parameters are estimated through procedures of maximum likelihood considering the censored observations and assuming the duration for each individual is independent of the others.

In empirical studies, it is often the case that adoption time occurs at discrete time intervals. The annual agricultural production cycle makes that particularly relevant for agricultural innovations, because they tend to be adopted for a specific growing season. Therefore, the model estimated in the current work follows discrete time steps in accordance with the annual nature of the decision-making process in cultivation systems (Burton et al., 2003). In these cases, the discrete hazard function can be expressed as follows (Meyer, 1990):

$$
h_{i t}=1-\exp \left\{-\exp \left[\gamma(t)+\beta^{\prime} X_{i t}\right]\right\}
$$

where $\gamma(t)=\ln \left\{\int_{t}^{t+1} h_{0}(s) d s\right\}$ and $\mathrm{X}_{\mathrm{it}}$ is the set of explanatory variables and includes crosssectional data and time-dependent variables for each case.

A reason for using this specification is that changes in the values of the exogenous timedependent variables are the same for all farmers, thus imparting a component of duration dependence that is equivalent for all individual adoption probabilities. Moreover, time-dependent variables are likely to capture most of the underlying time-dependent process of innovation diffusion.

Study area and data. This study focuses on the three main regions housing greenhouses in Spain, all of which are situated in the Mediterranean area. The areas analyzed are: LOCATION-1, found between Pilar de la Horadada (Alicante) and Campo de Cartagena (Murcia); LOCATION-2, mainly based in the municipalities of Lorca, Mazarrón, and Águilas (Murcia); and LOCATION-3, situated in El Ejido (Almería).The data used here were collected by 241 questionnaires given to greenhouse agricultural producers in the second semester of 2006.
Random sampling was stratified by growing areas. The population size comprised 6916 greenhouse owners with the strata corresponding to LOCATION 1 with 1888 owners and LOCATIONS 2 and 3 with 1314 and 3714 owners, respectively. The numbers of surveys are distributed by strata as follows: LOCATION 1 represents $27 \%$ of the sample, LOCATION 2 represents $19 \%$ of the total, and LOCATION 3 represents 54\%. If compared, the percentages of farmers comprised in each acreage range in the general farmer population are really similar to those in the sample frame in every area. From the total greenhouse growers and with a confidence level of $95 \%$, the sample generates an error of less than $6 \%$.

The data collection method was accomplished by personal and individual interviews of the greenhouse owners on the number indicated by the sample size chosen at random from the list of owners provided by agricultural extension services. After a pretest, these interviews were conducted by interviewers who are specialized technicians in the production carried out in these areas.

Most farms are family-run, although this does not necessarily guarantee generational takeover. Manual labor is under great demand most of the year, which can normally be satisfied by casual labor. There has been dynamic incorporation of the different technological improvements involving large capital investment. The high levels of greenhouse specialization, together with the auxiliary industries that have developed alongside, result in large coverage of the European demand by the Spanish freshmarket vegetables. The different ways of pooling the offer at origin have also played an important role, like the agricultural co- operatives and other social economy companies, which have become the main centers responsible for technological transfer in addition to their role in marketing production.

The questionnaire was divided into four blocks of questions, which collected data concerning: 1) farmers' personal and family data and the general characteristics of the farm, including the maximum level of greenhouse technology; 2) data concerning soilless cultivation: surface area, year of adoption, management difficulty, and so on; 3 ) other factors affecting the technological innovation process (farmers' information sources, training, marketing means, and so on); and 4) producer's environmental awareness.

Additional information was taken from official agricultural statistics and the environmental regulations concerning the use of MB during the period under analysis.

The initial hypothesis is that there are a number of factors affecting the speed at which innovation is adopted. Variables collected for the specific case of soilless cultivation are shown in Table 1. Following the outline by Pannell et al. (2006), the variables included in the study can be grouped according to the individual traits of the farmers questioned, which likewise depend on their personal characteristics, social factors, and crops. Other factors are added, which depend intrinsically on technology.

Figure 1 shows the number of farmers in the sample that adopted soilless cultivation from the moment the innovation is available to the year the data were taken. Adoption took place at the highest rate between 1998 and 2004 with very few early adoptions. Meanwhile, one can observe that in the last years, the number of farmers adopting this technology has leveled off or dropped.

\begin{tabular}{|c|c|}
\hline Variable & Meaning \\
\hline$\overline{\mathrm{AGE}}$ & Farmer's age \\
\hline ACREAGE & Greenhouse size (hectares) \\
\hline SON-RELIEVE & $1=$ if the farmer's children will take over; $0=$ otherwise \\
\hline INFO-SOURCE & $\begin{array}{l}1=\text { the farmer knew about the technology through information } \\
\text { from specialized personnel in agriculture (technology suppliers } \\
\text { or other inputs, agricultural extension services, cooperative } \\
\text { technicians or research centers); } 0=\text { the farmer knew about } \\
\text { the existence of the technology by seeing it on other farms }\end{array}$ \\
\hline EXT-LABOR & Number of workers, not relatives, hired a year \\
\hline ENVIRONMEN-C & $\begin{array}{l}1=\text { the farmer considers the environmental issue in the } \\
\text { decision-making process; } 0=\text { otherwise }\end{array}$ \\
\hline COOP-TRADE & $1=$ the farmer belongs to a cooperative; $0=$ otherwise \\
\hline LOCATION-1 & $\begin{array}{l}1=\text { if farm is located in Pilar de la Horadada } \\
\text { or Campo de Cartagena (Alicante and Murcia); } 0=\text { otherwise }\end{array}$ \\
\hline LOCATION-2 & $\begin{array}{l}1=\text { if farm is located in Lorca, Mazarrón } \\
\text { or Aguilas (Murcia); } 0=\text { otherwise }\end{array}$ \\
\hline LOCATION-3 & $1=$ if farm is located in El Ejido (Almería); $0=$ otherwise \\
\hline EXPORT $_{t}$ & $\begin{array}{l}\text { Tons of pepper exported in Spain the year before } \\
\text { of study period ( } t-1)\end{array}$ \\
\hline PEPPER-PRICE $_{t}$ & Pepper price in the study period (€/ kg) \\
\hline PEPPER & $1=$ if farmer grows pepper; $0=$ otherwise \\
\hline TOMATO & $1=$ if farmer grows tomato; $0=$ otherwise \\
\hline OTHER CROPS & $1=$ if farmer do not grow pepper and tomato; $0=$ otherwise \\
\hline MANAGEMENT & $\begin{array}{l}\text { Level of difficulty that the farmer has in managing } \\
\text { soilless cultivation }(0=\text { easy } \ldots 5=\text { difficult })\end{array}$ \\
\hline MBROMIDE-REST $_{\mathrm{t}}$ & $\begin{array}{l}\text { Percent of methyl bromide restriction according to the } \\
\text { Montreal Protocol in the study period }\end{array}$ \\
\hline
\end{tabular}

Table 1. Definitions of explanatory variables.

$t=$ time-varying variables. 
Farmers in the survey possessed an average greenhouse surface area of 2.65 ha. Generally they had achieved high crop specialization; $51.4 \%$ corresponded to peppers and $20.3 \%$ tomatoes. The main characteristics of the adopters and nonadopters of soilless cultivation can be seen in Table 2 . The age of the farmers adopting soilless cultivation was lower than those that did not. Likewise, the adopters had greater surface areas of greenhouses, a higher percentage of generational takeover, and more hired labor. The largest greenhouses using soilless cropping were found in Almería.

The time-dependent variables analyzed are given in Figure 2. The restrictions imposed on the use of MB began on 1998 and increased gradually until total prohibition in 2005 . One might expect that the higher the levels of $\mathrm{MB}$ restriction, the higher the levels of soilless cultivation adoption, because it is a direct alternative to deal with soil pathology. It is also possible that as export increases, for example, in pepper-growing, farmers seek to obtain larger higher-quality production, which soilless cultivation affords. Moreover, a relationship is expected to exist between the speed of soilless cultivation adoption and market prices of the analyzed productions.

\section{Results and Discussion}

The results derived from fitting Eq. 6 are estimated for three different specifications. Table 3 reports the maximum likelihood estimation of the parameters determining the adoption of soilless cropping systems of three models. Each of the three models presents a set of explanatory variables and, to select them, it is necessary to examine the significance of the variables and the robustness of the estimated parameters. Model 1 contains all the analyzed variables and Model 2 uses a specification that excludes those variables that were not statistically significant on the basis of t-values in Model 1, in which Model 2 is nested. In Model 3, the time-dependent variables are omitted to establish their degree of significance with the inclusion of these variables being one of the main advantages of DA.

Comparing the most general model, Model 1 with Model 2, it is possible to test the hypothesis that the coefficients of the variables EXT-LABOR ENVIRONMEN-C, COOP-TRADE, LOCATION1, PEPPER, and TOMATO are jointly zero given the likelihood ratio (LR) test statistically fails to reject the joint hypothesis $\left(\mathrm{LR}=6.47 ; \chi_{0.05,6}^{2}=\right.$ 12.59). Moreover, one can see that the estimated coefficients for the variables of Model 2 are very similar to those estimated in Model 1. Likewise, on comparing Model 2 with Model 3, the LR test shows that the coefficients of the time-dependent variables are equal to 0 , but the hypothesis is rejected ( $\mathrm{LR}=10.78$; $\left.\chi_{0.05,4}^{2}=9.49\right)$. Therefore, Model 2 specification is preferable, and the final results will be interpreted taking this as a base.

The proportional hazard model is parameterized by a Weibull distribution with pos-

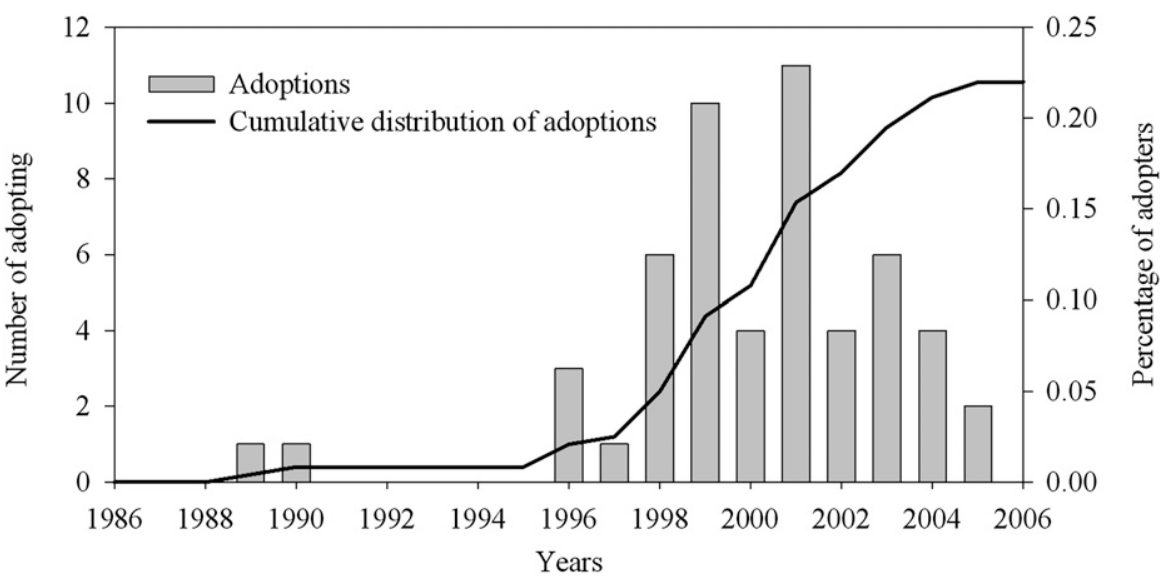

Fig. 1. Adoption of soilless technology in sample (1986 to 2005).

Table 2. Descriptive statistics for the time invariant variables in the adoption model for soilless cropping in Mediterranean greenhouses.

\begin{tabular}{|c|c|c|c|c|c|c|c|c|}
\hline \multirow[b]{2}{*}{ Variable name } & \multicolumn{4}{|c|}{ Adopters } & \multicolumn{4}{|c|}{ Nonadopters } \\
\hline & $\overline{\text { Mean }}$ & SD & Minimum & Maximum & Mean & $\mathrm{SD}$ & Minimum & Maximum \\
\hline$\overline{\mathrm{AGE}}$ & 37.72 & 9.02 & 22 & 62 & 41.38 & 11.08 & 19 & 73 \\
\hline ACREAGE & 3.63 & 4.31 & 0.6 & 26 & 2.38 & 2.26 & 0.2 & 20 \\
\hline SON-RELIEVE & 0.30 & 0.46 & 0 & 1 & 0.16 & 0.37 & 0 & 1 \\
\hline INFO-SOURCE & 0.58 & 0.50 & 0 & 1 & 0.14 & 0.35 & 0 & 1 \\
\hline EXT-LABOR & 9.05 & 19.67 & 0 & 125 & 3.15 & 4.57 & 0 & 33 \\
\hline ENVIRONMEN-C & 0.55 & 0.50 & 0 & 1 & 0.47 & 0.50 & 0 & 1 \\
\hline COOP-TRADE & 0.64 & 0.48 & 0 & 1 & 0.57 & 0.50 & 0 & 1 \\
\hline LOCATION-1 & 0.28 & 0.45 & 0 & 1 & 0.27 & 0.44 & 0 & 1 \\
\hline LOCATION-2 & 0.09 & 0.29 & 0 & 1 & 0.22 & 0.41 & 0 & 1 \\
\hline LOCATION-3 & 0.62 & 0.49 & 0 & 1 & 0.51 & 0.50 & 0 & 1 \\
\hline PEPPER & 0.52 & 0.50 & 0 & 1 & 0.51 & 0.50 & 0 & 1 \\
\hline TOMATO & 0.15 & 0.36 & 0 & 1 & 0.22 & 0.41 & 0 & 1 \\
\hline OTHER CROPS & 0.33 & 0.48 & 0 & 1 & 0.27 & 0.44 & 0 & 1 \\
\hline MANAGEMENT & 2.91 & 0.99 & 1 & 5 & 3.41 & 1.08 & 1 & 5 \\
\hline Number of observations & 53 & & & & 188 & & & \\
\hline
\end{tabular}

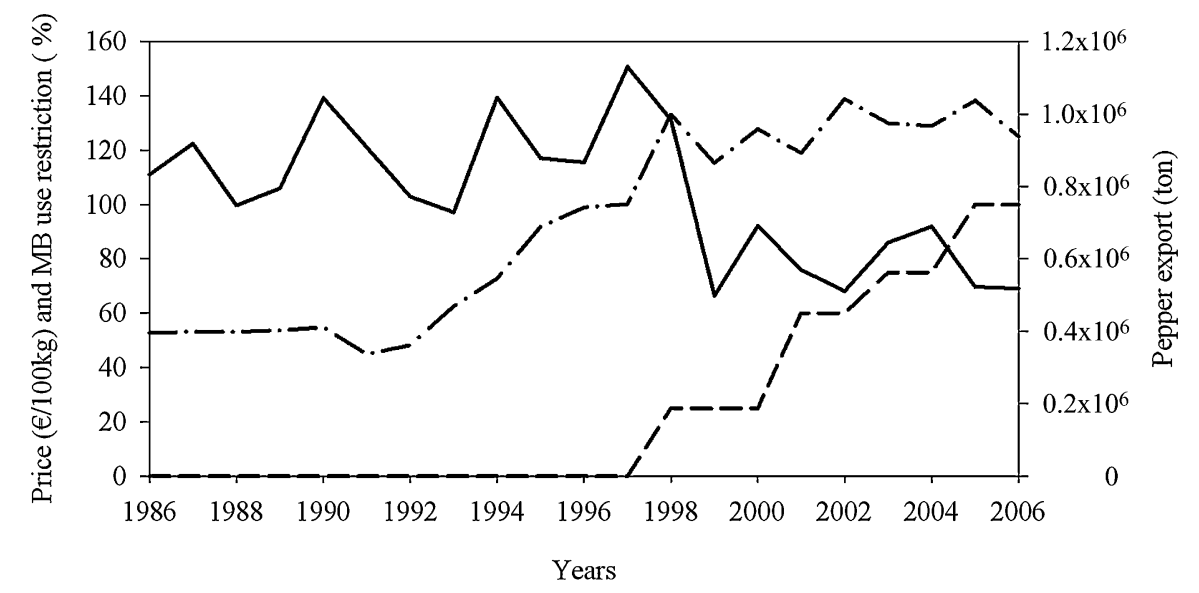

— Deflated pepper price $(€ / 100 \mathrm{~kg})-$ - - Pepper export t-1 (ton) - - $\cdot$ MB use restriction (\%)

Fig. 2. Time-dependent variables along the period 1986 to 2006. Pepper exportations in the year t-1; methyl bromide use restriction; and deflated pepper price.

itive time dependence. A LR test for the exponential form gives a $\chi_{0.05,1}^{2}$ statistic of 32.30 , rejecting the hypothesis of nonduration dependence baseline hazard function.

The estimated coefficients give $\beta$ values that are interpreted as the proportional change of the hazard function achieved by a marginal change in the explanatory variable and its sign shows the direction of the impact on the hazard function. These coefficients should be interpreted as $\exp (\beta)$, where values equal to 1 imply no impact on the hazard function. However, values higher (lower) than 1 indicate a positive impact (negative) on the hazard, thus the negative relationship between the variable and the adoption time.

Model 2 includes a total of nine significant variables, which encompass the social, 
Table 3. Estimates of alternative specification of Weibull hazard functions for soilless technology adoption.

\begin{tabular}{|c|c|c|c|c|c|c|}
\hline & \multicolumn{2}{|c|}{ Model 1} & \multicolumn{2}{|c|}{ Model 2} & \multicolumn{2}{|c|}{ Model 3} \\
\hline & Coefficient & SE & Coefficient & SE & Coefficient & SE \\
\hline$\overline{\mathrm{AGE}}$ & -0.16 & $-0.03 * * *$ & -0.16 & $0.27 * * *$ & -0.16 & $0.02 * * *$ \\
\hline ACREAGE & 0.26 & $0.06 * * *$ & 0.26 & $0.05 * * *$ & 0.25 & $0.05 * * *$ \\
\hline SON-RELIEVE & 0.80 & $0.35^{*}$ & 0.81 & $0.32 * *$ & 0.88 & $0.32 * *$ \\
\hline INFO-SOURCE & 1.29 & $0.31 * * *$ & 1.33 & $0.30 * * *$ & 1.46 & $0.20 * * *$ \\
\hline EXT-LABOR & 0.01 & 0.01 & & & & \\
\hline ENVIRONMEN-C & 0.12 & 0.32 & & & & \\
\hline COOP-TRADE & 0.43 & 0.33 & & & & \\
\hline LOCATION-1 & -0.05 & 0.42 & & & & \\
\hline LOCATION-2 & -2.47 & $1.09 *$ & -1.46 & $0.64 *$ & -1.553 & $0.66^{*}$ \\
\hline EXPORT $_{t}$ & $3.01 \mathrm{e}-6$ & $1.49 \mathrm{e}-6^{*}$ & $2.74 \mathrm{e}-6$ & $1.39 *$ & & \\
\hline PEPPER-PRICE $_{t}$ & -0.02 & $0.01 *$ & -0.02 & $0.01 *$ & & \\
\hline PEPPER & -0.62 & 0.37 & & & & \\
\hline TOMATO & 0.10 & 0.68 & & & & \\
\hline MANAGEMENT & -0.50 & $0.16^{*}$ & -0.44 & $0.15 * *$ & -0.414 & $-2.71 * * *$ \\
\hline MBROMIDE-REST $_{t}$ & 0.02 & $0.01 * *$ & 0.02 & $0.01 * *$ & & \\
\hline Cons & -6.48 & $2.01 * * *$ & -6.77 & $1.98 * * *$ & -5.01 & $1.16 * * *$ \\
\hline$(\mathrm{p}-1)$ & 2.81 & $0.70 * * *$ & 2.90 & $0.711 * * *$ & 2.99 & $0.46 * * *$ \\
\hline Log likelihood & -198.899 & & -202.136 & & -207.529 & \\
\hline AIC & 0.107 & & 0.106 & & 0.107 & \\
\hline $\begin{array}{l}\text { Number of } \\
\text { observations }\end{array}$ & 241 & & 241 & & 241 & \\
\hline
\end{tabular}

Significance levels at $* P<0.05, * * P<0.01$, and $* * * P<0.001$.

$t=$ time-varying variables.

Model 1 contains all the analyzed variables.

Model 2 uses a more parsimonious specification that excludes those variables that were not statistically significant in Model 1.

Model 3 omits time-dependent variables from Model 2.

cultural, and personal influences of the potential adopters and other attributes of the technology itself. Of these variables, six are statistically significant at $99 \%$ or higher to explain the conditional probabilities of adopting soilless cultivation.

Inclusion of time-varying variables representing product export data series (EXPORT) and prices (PEPPER-PRICE) as well as legal restriction on MB use (MBROMIDE-REST) has proven to be significant (Model 2 versus Model 3). This demonstrates the importance of including these variables and the existence of an underlying time-dependent process of innovation diffusion by which farmers learn about the technology, which enables them to reduce inherent uncertainty and assist decision-making, at least in cases in which technology adoption can contribute to achieving farmers' own objectives, as reported by Marra et al. (2003).

The personal characteristics influencing adoption decisions include the farmer's age (AGE). Although a mixed response can be found in the literature (Rogers, 2003), in our study, age was found to exert a negative effect on the likelihood of adopting soilless cultivation, confirming that the older farmers have less incentive to adopt this package.

When there is a family successor on the farm, who will benefit from investment in this technology and training required by its adoption, measured as the variable SONRELIEVE, the conditional probability of farmers adopting it is more than doubles that of farmers who have no generational takeover perspectives.

The positive coefficient for the variable ACREAGE indicates that the farmers possessing a greater greenhouse surface area tend to increase the global benefit of adoption and, with it, the conditional probability of adoption. Generally, large farm owners have been more innovative as a result of the fact they can bear the fixed costs of implementing the technology more easily as well as having the capital necessary for its acquisition (Feder and Umali, 1993). Normally, the large greenhouses are more business-like in nature and hire labor from outside the family; however, in our study, the variable EXTLABOR was not statistically significant.

The variable INFO-SOURCE confirms that when the farmers obtain technical information from people they consider to be experts, adoption speed is greater than those who learned about the technology by seeing it on other farms but did not seek professional advice.

Among the social influences affecting adoption speed, LOCATION-2 was the production area that proved to be significant. Moreover, this area is highly specialized in tomato-growing, and this crop does not require high-demanding management given that it is highly adapted to the Mediterranean agro ecological conditions. In addition, high income levels are not guaranteed, which means investment in technology is delayed.

Comparing the two main production zones (LOCATION 1 and 3), significant differences are not found between them. This would indicate that no external social factors benefit the spread of soilless cultivation in the main production regions, contrary to that indicated by Abdulai and Huffman (2005).

On the other hand, and given the agricultural advantages of soilless cultivation, the productive cycle can be extended and better quality harvests obtained, thus increasing export potential. It is supported by the variable EXPORT for a year $t-1$, which provides the farmer with important information for decisions made for the following campaign.

There is a response to pepper prices (PEPPER-PRICE), in that when these decrease, the change in probability rates increase. This shows that the farmer has adopted soilless cultivation to benefit from the relative advantage it gives and thus aspires to better market prices. Moreover, this technique affords advantages in a relatively short time, so this also favors adoption speed, as reported by Marsh et al. (2000). Furthermore, GarcíaMartínez et al. (2008) demonstrated that pepper prices in the Spanish greenhouses increase considerably when there is production outside the traditional harvesting epochs, focusing on the spring months in particular, and soilless cultivation is necessary to achieve this.

The farmer's personal perception of the set of relative advantages afforded by soilless cultivation technology, and to what extent it can help achieve personal goals, can be partially set back if the farmers perceive the technology as difficult to manage. Thus, the value showing the marginal effect exerted by the variable MANAGEMENT confirms that adoption takes longer when farmers perceive technology management to be more difficult. Therefore, in these cases, farmers need to be better informed beforehand about the consequences of adoption (Rogers, 2003).

In the same way, the policies regulating the use of MB (MBROMIDE-RESTR), given the environmental problems it poses, also affect the hazard function. As restrictions of MB use have increased, in line with the Montreal Protocol, the rates in the adoption probability changes have also increased. This increase in adoption speed shows that the use of soilless cultivation not only affords productive advantages, but is also a clear alternative to solving soil-associated problems and can be quickly implemented by farmers faced with the impossibility of using MB.

Other variables analyzed in this study, which were initially expected to be significant, have turned out not to be so in our proportional hazard model. For example, the type of crop was not significant. Belonging to an agricultural association also exerted an influence on technology adoption according to Kington and Pannell (2003), as did the farmers' environmental awareness with favorable effects on the adoption of different soil-conservation practices (Pannell et al., 2006). Nevertheless, the variables PEPPER, TOMATO, ENVIRONMEN-C, and COOPTRADE did not have a significant impact on soilless cultivation adoption speed in Spanish Mediterranean greenhouses.

It is possible that there are unidentified random influences, which have not been specified by the hazard function in the duration models. To identify this possible flaw and validate the final quality of our model, considering that the specification may be incomplete, an unobserved heterogeneity component has been incorporated following the gamma distribution in accordance with the work by Meyer (1990). After its estimation, following 
the procedure put forward by Jenkins (1995), unobserved heterogeneity did not pose a serious problem in this case. Therefore, one can assume that the functional form chosen in the present work is suitable for this scenario.

\section{Conclusion}

The present study has analyzed the dynamics of the timing of soilless technology adoption in greenhouses in the Spanish Mediterranean region using DA.

DA estimates farmers' timing in adopting soilless cultivation associated with their personal characteristics, the surroundings, and aspects inherent to the technology itself. This methodology affords an improvement over the traditionally used models. The results suggest that the conditional probability of adopting soilless cultivation technology positively depends on timing and that farmers' personal characteristics, like being younger, owning larger greenhouse surface areas, the family's intention to continue working the farm, and the fact that farmers receive information from professionals and do not just imitate neighboring farms, are all factors exerting a positive influence on adoption speed.

Furthermore, the conditional probability of adopting soilless cultivation is increased by commercial perspectives with the latter being influenced by the price, which in turn depends on quality. Thus, higher exports or decreasing prices stimulate farmers to adopt, so that they can obtain better quality products and achieve higher prices.

The present study confirms the importance of the timing of knowledge acquisition, thereby diminishing uncertainties about the technology and encouraging better decisionmaking. In this respect, although soilless cultivation affords farmers numerous advantages and is a technique that can lessen certain negative external factors derived from intensive soil cultivation, it has not spread with sufficient speed in Spanish Mediterranean greenhouses. This demonstrates that currently the economic and commercial aspects of vegetable production still exert a stronger influence on the final decision to invest in soilless cultivation technology and are, therefore, the variables that speed up (or not) adoption to a greater extent.

These results contribute to a better understanding of the adoption process as a whole; thus, farmers can be helped to achieve their goals when seeking more knowledge about technology and its performance. Also, better informed policymakers and extension services are desirable if, given the current environmental and economic concerns, more widespread use of this technology would help develop rural areas and improve agricultural revitalization.

The delay in adopting profitable technologies, described by this approach, could be complemented by other predictive approaches such as real options, which allow us to estimate the optimal adoption time, taking into account the irreversibility and uncertainty of the investment. There is a direct relationship between these two approaches, because the real options method provides the trigger value of the output price or yield that indicates when the investment should be made considering the option value of delaying adoption within an economic framework.

\section{Literature Cited}

Abadi-Ghadim, A.K. and D.J. Pannell. 1999. A conceptual framework of adoption of an agricultural innovation. Agr. Econ. 21:145-154.

Abdulai, A. and W.E. Huffman. 2005. The diffusion of new agricultural technologies: The case of crossbred-cow technology in Tanzania. Amer. J. Agr. Econ. 87:645-659.

Aramyan, L.H., A.G.J.M. Lansink, and J.A.A.M. Verstegen. 2007. Factors underlying the investment decision in energy-saving systems in Dutch horticulture. Agr. Syst. 94:520-527.

Burton, M., D. Rigby, and T. Young. 2003. Modelling the adoption of organic horticultural technology in the UK using duration analysis. Aust. J. Agr. Resour. Econ. 47:29-54.

Doss, C.R. 2006. Analyzing technology adoption using microstudies: Limitations, challenges, and opportunities for improvement. Agr. Econ. 34:207-219.

Engindeniz, S. 2004. Economic analysis of growing greenhouse cucumber with soilless culture systems: The case of Turkey. J. Sustain. Agr. 23:5-19.

FAO. 2002. Cultures protégées en climat méditerranéen. Etude FAO: Production Végétale et Protection des Plantes (FAO), 90. Rome, Italy.

Feder, G. and D.L. Umali. 1993. The adoption of agricultural innovations: A review. Technol. Forecast. Soc. 43:215-239.

García-Martínez, M.C., P. Caballero, and M.A. Fernández-Zamudio. 2008. Price trends in greenhouse tomato and pepper and choice of adoptable technology. Span. J. Agr. Res. 6: 320-332.

Garibaldi, A., A. Minuto, V. Grasso, and M.L. Gullino. 2003. Application of selected antagonistic strains against Phytopthora criptogea on gerbera in closed soilless systems with disin- fection by slow sand filtration. Crop Prot. 22:1053-1061.

Gatignon, H. and T.S. Robertson. 1991. Innovative decision processes, p. 316-348. In: Robertson, T.S. and H.H. Kassarjian (eds.). Handbook of consumer behavior. Prentice-Hall, Englewood Cliffs, NJ.

Hall, T.J., J.H. Dennis, R.G. Lopez, and M.I. Marshall. 2009. Factors affecting growers' willingness to adopt sustainable floriculture practices. HortScience 44:1346-1351.

Jenkins, S.P. 1995. Easy estimation methods for discrete-time duration models. Oxf. Bull. Econ. Stat. 57:129-138.

Kiefer, N.M. 1988. Economic duration data and hazard functions. J. Econ. Lit. 26:646-679.

Kington, E.A. and D.J. Pannell. 2003. Dryland salinity in the Upper Kent River catchment of Western Australia: Farmer perceptions and practices. Aust. J. Exp. Agr. 43:19-28.

Lancaster, T. 1972. A stochastic model for the duration of a strike. J. R. Stat. Soc. [Ser A] 135: 257-271.

Lancaster, T. 1990. The econometric analysis of transition data. Cambridge University Press, Cambridge, UK.

MAPA. 2006. Anuario de estadística agroalimentaria. Ministerio de Medio Ambiente y Medio Rural y Marino, Madrid, Spain.

Marra, M., D.J. Pannell, and A.K. Abadi-Ghadim. 2003. The economics of risk, uncertainty and learning in the adoption of new agricultural technologies: Where are we on the learning curve? Agric. Syst. 75:215-234.

Marsh, S.P., D.J. Pannell, and R.K. Lindner. 2000. The impact of agricultural extension on adoption and diffusion of lupins as a new crop in Western Australia. Aust. J. Exp. Agric. 40:571-583.

Meyer, B.D. 1990. Unemployment-insurance and unemployment spells. Econometrica 58:757782.

Pannell, D.J., G.R. Marshall, N. Barr, A. Curtis, F. Vanclay, and R. Wilkinson. 2006. Understanding and promoting adoption of conservation practices by rural landholders. Aust. J. Exp. Agr. 46:1407-1424.

Ransom, J.K., K. Paudyal, and K. Adhikari. 2003. Adoption of improved maize varieties in the hills of Nepal. Agr. Econ. 29:299-305.

Rogers, E.M. 2003. Diffusion of innovations. Free Press, New York, NY.

Seo, S., E. Segarra, P.D. Mitchell, and D.J. Leatham. 2008. Irrigation technology adoption and its implication for water conservation in the Texas High Plains: A real options approach. Agr. Econ. 38:47-55.

Smith, M.D. 2004. Limited-entry licensing: insights from a duration model. Amer. J. Agr. Econ. 86:605-618.

Van Os, E.A. 1999. Closed soilless growing systems: A sustainable solution for Dutch greenhouse horticulture. Water Sci. Technol. 39: $105-112$. 